\title{
Pharmacological Analysis of the Potentiation of Carrageenin-Induced Paw Oedema by Reactive Blue 2
}

\author{
Stefano Evangelista* \\ Independent Pharmacologist, Italy \\ Received: February 13, 2018; Published: February 20, 2018 \\ *Corresponding author: Stefano Evangelista, Independent Pharmacologist, Via Giordani 2, 50121 Firenze, Italy, Email: evangels@alice.it
}

\begin{abstract}
Reactive blue 2 is an a specific antagonist of the ATP P2X and P2Y receptors that are ligand-gated ion channels widely distributed in the organism and that serve as control of excitability of their host cells. Due to the known involvement of ATP in inflammatory and pain processes, we have evaluated the pro-inflammatory effect of reactive blue 2 in the paw oedema induced by carrageenin in rats. Reactive blue 2 did not by itself induce paw oedema but enhanced all phases of the inflammatory response induced by carrageenin. In the first phase of the oedema (0-1 h), compound 48/80, but not the serotonin and histamine receptor antagonists cimetidine, cyproeptadine and diphenydramine, counteracted the pro-oedema effect of reactive blue 2 . The second phase $(0-2 \mathrm{~h})$ of carrageenin+reactive blue 2 was markedly antagonized by hexadimethrine, a heparin antagonist. The late phase, characterized by prostaglandins involvement was partly antagonized by the dual antagonist of cycloxigenase and lipoxygenase BW 755 and by dexamethasone, but not by indomethacin. The modulating effect of reactive blue 2 on ATP via other autacoids such as heparin is probably responsible on its pro-inflammatory effects.
\end{abstract}

Key words: Adenosine-5’-Triphosphate (ATP); Carrageenin; Inflammation; Reactive Blue 2

\section{Introduction}

Reactive blue 2 is an anthraquinone-sulphonic acid derivative which exerts P2 receptor antagonistic properties [1,2]. Reducing the effect on ATP in several systems [3]. It has been shown that it is able to allosterically modulate the receptor P2X and P2Y that regulate the activity of ATP through ligand-gated ion channels and are involved in excitability of the cells. Reactive blue 2 was able to not only reduce the ATP-induced relaxation of rat duodenum but also to potentiate the prostaglandin-mediated phase of rebound contraction of this preparation [4]. Moreover the involvement of extracellular ATP in pain and mechanic sensitive afferent-mediated processes [5-7]. prompted us to assess the potential effect of reactive blue 2 on the classical model of acute inflammation such as carrageenin-induced paw edema.

\section{Material and Methods}

Carrageenin-induced oedema in rat's Male albino SpragueDawley rats weighing 110-130 g was used. BW755 and indomethacin were suspended in an aqueous vehicle containing $\mathrm{NaCl} 0.9 \%$, Tween $800.4 \%$ and carboxymethylcellulose $0.5 \%$ while compound $48 / 80$, hexadimethrine and reactive blue 2 were dissolved in saline.
All substances were administered in a volume of $5 \mathrm{ml} / \mathrm{kg}$ one hour before the injection of carrageenin and/or reactive blue 2 except compound 48/80 which was administered for 3 days before the test and were given at the active doses described previously [8-10]. Paw oedema was induced as described by Winter [11]. $0.1 \mathrm{ml}$ of $0.5 \%$ suspension of carrageenin (type IV) or $0.025-0.1 \%$ of reactive blue 2 or both were injected into the plantar aponeurosis of the right hind paw. Foot volume was measured immediately following the paw injection and 1, 2, 3 and 5 h later by means a mercury plethysmometer (Basile, Varese, Italy).

\section{Data analysis}

All data in the text are means + S.E.M. Statistical significance was evaluated by means of one-way analysis of variance followed by Dunnett's test.

\section{Drugs}

BW755 (Wellcome); Carrageenin (Type IV; Sigma); Cimetidine (Sigma); Cyproeptadine (Sigma); Compound 48/80 (Sigma); Dexamethasone (Sigma); Diphenidramine (Sigma): Hexadimethrine (Sigma); Indomethacin (Merck); Reactive blue 2 (Sigma). 


\section{Results}

As shown in Fig. 1 reactive blue 2, which are inactive when injected alone up to the concentration of $0.1 \%$, potentiated in a dose-dependent manner all phases of development of carrageenininduced paw oedema.

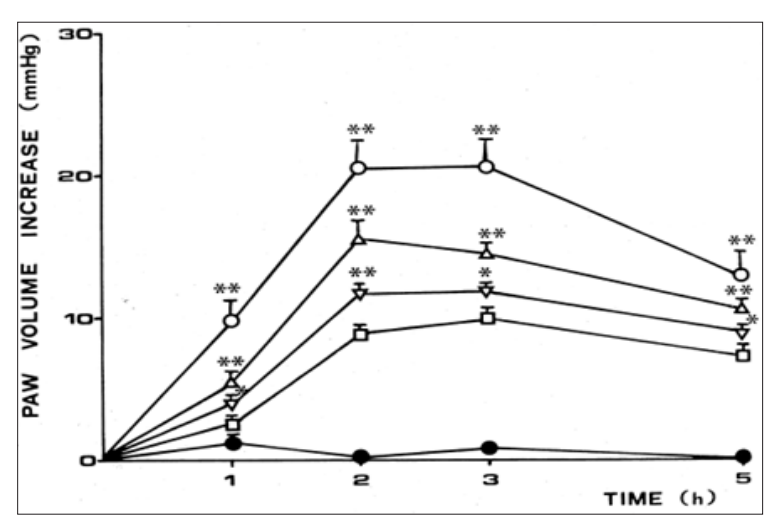

Figure 1: Reactive blue 2 enhancement of carrageenininduced paw oedema. (black circles) $=$ reactive blue $20.1 \%$; (squares) = carrageenin; $($ reversed triangles $)=$ carrageenin + reactive blue $20.025 \%$; (normal triangles) = carrageenin + reactive blue $20.05 \%$; (white circles) = carrageenin + reactive blue $20.1 \% . n=7$ for all groups. ${ }^{*}=p<0.05$ and ${ }^{* *}=$ $\mathrm{p}<0.01$ as compared to carrageenin group.

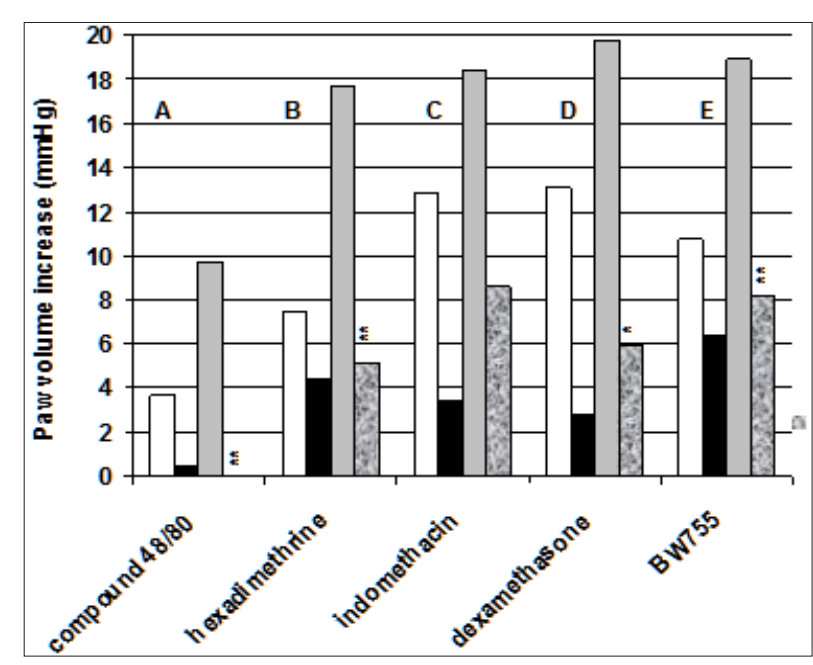

Figure 2: Effect of A) compound 48/80, B) hexadimethrine, C) indomethacin, D) benoxaprofen, E) BW755 on reactive blue 2 enhancement of carrageenin-induced paw oedema at 1 (A), 2 (B) and 3 (C, D, E) hours after the paw injection.

Compound 48/80 $1 \mathrm{mg} / \mathrm{kg}$ i.p. for three days (Figure 1) but not the classical antagonists of 5HT (cyproeptadine $10 \mathrm{mg} / \mathrm{kg}$ i.p.), $\mathrm{H} 1$ (diphenidramine $10 \mathrm{mg} / \mathrm{kg}$ i.p.) and $\mathrm{H} 2$ (cimetidine $10 \mathrm{mg} / \mathrm{kg}$ i.p.) receptors antagonized paw oedema development in presence or absence of reactive blue 2. Paw oedema at $1 \mathrm{~h}$ was $2.57+1.16$ and $3.92+0.72$ in carrageenin and carrageenin+RB2 groups treated with the vehicle and $1.42+1.0$ and 2.0+0.6 in carrageenin and carrageenin+RB2 groups treated with the cyproeptadine (F interaction $=0.18$, n.s.) and $1.85+0.61$ and 5.5+0.72 in carrageenin and carrageenin $+\mathrm{RB} 2$ groups treated with the diphenidramine $(\mathrm{F}$ interaction $=1.87$, n.s.) and $1.42+0.52$ and $4.4+1.1$ in carrageenin and carrageenin+RB2 groups treated with the cimetidine (F interaction $=0.79$, n.s.). Hexadimethrine $25 \mathrm{mg} / \mathrm{kg}$ i.p. significantly inhibited the second phase of development of carrageenin paw but was even more effective in inhibiting carrageenin + reactive blue 2-induced paw oedema formation (Figure 2). The degree of development of prostaglandins-dependent oedema (third phase) was significantly reduced by either indomethacin ( $2 \mathrm{mg} / \mathrm{kg}$ p.o.). However indomethacin did not reduce the potentiating effects of reactive blue 2 (Figure 2) which, on the other hand, was significantly decreased by dexamethasone $0.1 \mathrm{mg} / \mathrm{kg}$ p.o. (Figure 2) or BW755 $50 \mathrm{mg} / \mathrm{kg}$ p.o. (Figure 2).

\section{Discussion}

The pivotal paper of Di Rosa [8]. has let the characterization of the mediators of oedema induced by carrageenin in the rat paw. In dependence of the mediator involved, the authors have divided this reaction in three phases. The first phase is dependent on the sudden release of histamine and 5-HT from mast-cells. The compound $48 / 80$, a mast-cells and complement depletory [8]. Blunted the oedema, being these cells and the concomitant release of mediators necessary for the start of the inflammatory reaction.

Reactive blue 2, which by itself did not produce oedema at any phase tested, potentiated the carrageenin effect on the paw. The analysis of H1, H2 or 5-HT receptor through the use of the selective antagonists such as diphenidramine, cimetidine or cyproeptadine, respectively, indicates that the potentiation of the oedema is not mediated by these autacoids. The so-called second phase is characterized by the intervention of complement and heparin. It is noteworthy that hexadimethrine, a heparin antagonist which exerts also complement inhibiting activity [12-14]. Was able to markedly decrease the paw oedema induced by carrageenin and reactive blue 2 . Reactive blue 2 is known to modulate the activity of ATP by the receptor P2X and P2Y $[15,16]$. Present also in vascular endothelial cells [17]. Moreover ATP, among the several functions carried out as pivotal mediators in many cell reactions, was able to neutralize the effect of heparin [18]. It is tempting to speculate that the pro-inflammatory effect of reactive blue 2 is mainly due to the free release of heparin.

At the third hour after carrageenin injection in the paw there is the peak of the oedema and this phase is known to be prostaglandins dependent $[8,19]$. Indomethacin was unable to affect the enhancing effect of reactive blue 2 while dexamethasone and the dual cycloxigenase and lipoxygenase BW 755 decreased, at least in part, the oedematous reaction induced by reactive blue 2 in presence of carrageenin. From these data it seems that reactive blue 2 activate the lipoxygenase pathway in enhancing this phase of the inflammation. It should be noted also that the clone P2Y7, originally suggested to be a P2Y receptor, has been shown to encode a leukotriene receptor so showing a great homology among the receptors [20]. From these findings it seems that ATP act as an allosteric regulator during acute inflammation and when its receptor 
P2X and P2Y that regulate the activity of ATP through ligand-gated ion channels are blocked, some autacoids involved and released in the inflammation are not counteracted producing an exaggerated inflammatory response. Similar results were obtained in mice lacking P2X receptors that express greater sensitivity to thermal inflammation and hyperalgesia [5]. Reactive blue 2 markedly enhanced all phases of carrageenin oedema, its ATP inhibiting activity and thus the interference with heparin and leukotrienes seems to be involved in these pro-inflammatory effects. The better knowledge of the mechanisms involved in inflammation can help to develop new drugs in this complex process that is primary in a lot of diseases.

\section{References}

1. Kerr D, A Krantis (1979) A new class of ATP antagonists. Proc Aust Physiol Pharmac Sect 10, pp156.

2. Crema A, Lecchini S, Manzo L, Onori L, M Tonini (1983) Purine receptors in the guinea pig internal anal sphincter. Br J Pharmacol 78 (3): 599-603.

3. Von Kügelgen I (2006) Pharmacological profiles of cloned mammalian P2Y-receptor subtypes. Pharmacol Ther 110 (3): 415-432.

4. Maggi CA, Manzini S, A Meli (1984) Evidence that GABAA receptors mediate relaxation of rat duodenum by activating intramural nonadrenergic noncholinergic neurons. J Autonom Pharmacol 4 (2): 77 85.

5. Souslova V, Cesare P, Ding Y, Akopian AL, Stanfa L, et al. (2000) Warmcoding deficits and aberrant inflammatory pain in mice lacking $\mathrm{P} 2 \mathrm{x} 3$ receptors. Nature 407: 1015-1017.

6. Oliveira MC, Pelegrini Da Silva A, Tambell CH, CA Parada (2009) Peripheral mechanisms underlying the essential role of P2X3, 2/3 receptors in the development of inflammatory hyperalgesia. Pain 141 (1-2): 127-134.

7. Burnstock G (2017) Purinergic signalling: therapeutic developments. Front Pharmacol 8: pp661.

8. Di Rosa M, Giroud JP, DA Willoughby (1971) Studies of the mediators of the acute inflammatory response induced in rats in different sites by carrageenin and turpentine. J Pathol 104 (1): 15-29.
9. Higgs GA, Eakins KE, Muridge KG, Moncada S, JR Vane (1980) The effects of non-steroid anti-inflammatory drugs on leukocyte migration in carrageenin-induced inflammation. Eur J Pharmacol 66 (1): 81-86.

10. Salmon JA, Simmons PM, S Moncada (1983) The effects of BW755c and other anti-inflammatory drugs on eicosanoid concentrations and leukocyte accumulation in experimentally-induced acute inflammation. J Pharm Pharmacol 35 (12): 808-813.

11. Winter CA, Risley EA, GW Nuss (1962) Carrageenin-induced paw oedema in hind paw of the rat and assay for anti-inflammatory drugs. Proc Soc Exp Biol Med 111: 544-547.

12. Nielsen EW, Johansen HT, Straume B, TE Mollnes (1994) Effect of time, temperature and additives on a functional assay of $\mathrm{C} 1$ inhibitor. J Immunol Meth 173 (2): 245-251.

13. Kikura M, Lee MK, JH Levy (1996) Heparin neutralization withy methylene blue, hexadimethrine, or vancomycin after cardiopulmonary bypass. Anesth Analg 83 (2): 223-227.

14. Armstrong D, JW Stewart (1962) Antiheparin agents as inhibitors of plasma kinin-formation. Nature 194: 689.

15. Alexander K, Niforatos W, Bianchi B, Burgard EC, Lynch KG, et al. (1999) Allosteric modulation and accelerated resensitization of human P2X(3) receptors by bibacron blue. J Pharmacol Exp Ther 291 (3): 1135-1142.

16. Communi D, Robaye B, JM Boeynaems (1999) Pharmacological characterization of the human P2Y11 receptor. Br J Pharmacol 128 (6): 1199-1206.

17. Viana F, de Smedt H, Droogmans G, B Nilius (1998) Calcium signalling through nucleoside receptor P2Y2 in cultured human vascular endothelium. Cell Calcium 24 (2): 117-127.

18. Dietrich CP, Shinjo SK, Moraes FA, Castro RA, Mendes A, et al. (1999) Structural features and bledding activity of commercial low molecular weight heparins: neutralization by ATP and protamine. Semin Thromb Hemost 25 (S3): 43-50.

19. Winter CA, Risley EA, GW Nuss (1963) Anti-inflammatory and antipyretic activities of indomethacin, 1-(p-chlorobenzyl)-5-methyl-indole-3-acetic acid. J Pharmacol Exp Ther 141: 369-376.

20. Yokomizo T, Izumi T, Chang K, Taqkuwa Y, T Shimizu, (1997) A G-proteincoupled receptor for leukotriene B4 that mediates chemotaxis. Nature 387 (6633): 620-624.

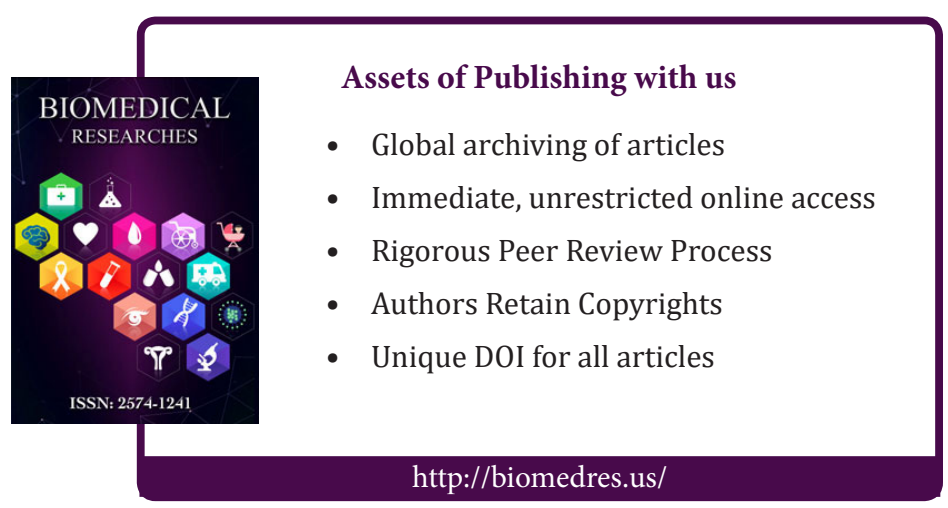

